\title{
Effects of transfusion load and suction pressure on renal function in intraoperative salvage autotransfusion
}

\author{
Jingyang Zeng ${ }^{1 *}$, Sijie Zhang ${ }^{2 *}$, Qilin $\mathrm{Wu}^{2 \oplus}$, Shunyuan $\mathrm{Li}^{1 \oplus}$, Yingle Chen ${ }^{1 \oplus}$, and Biyu $\mathrm{Wu}^{3 \odot}$ \\ ${ }^{1}$ Department of Anesthesiology, Quanzhou First Hospital Affiliated to Fujian Medical University, Quanzhou, Fujian, China \\ ${ }^{2}$ Graduate School of Fujian Medical University, Fuzhou, Fujian, China \\ ${ }^{3}$ Department of Nursing, Quanzhou First Hospital Affiliated to Fujian Medical University, Quanzhou, Fujian, China
}

\begin{abstract}
Although some investigations have been performed to determine the effects of transfusion load and suction pressure on renal function during intraoperative salvage autotransfusion, the precise threshold is still undetermined. A total of 625 patients undergoing surgery with the Continuous AutoTransfusion System (CATS ${ }^{\text {plus }}$ ) were enrolled and divided into groups according to the utilized suction pressure and transfusion volume. Plasma free hemoglobin (FHB) and creatinine clearance (CCr) were assayed to indicate the renal function. Both $0.03 \mathrm{MPa}$ suction ( $\geqslant 4$-unit load) and $>5$ units transfusion changed the levels of $\mathrm{FHB}$ and $\mathrm{CCr}$ significantly when measured $24 \mathrm{~h}$ post-operation compared to pre-operation. Under $0.02 \mathrm{MPa}$ suction ( $\geqslant 4$-unit load), the alteration of FHB and CCr returned to normal after $24 \mathrm{~h}$. Under 3 units transfusion, the levels of FHB and CCr at 6 and $12 \mathrm{~h}$ post-operation changed significantly compared to pre-operation $(\mathrm{P}<0.05$ or $\mathrm{P}<0.01$, respectively), and this alteration could be restored to normal at $72 \mathrm{~h}$ post-operation. After an exhaustive investigation, less than 4 units transfusion and less than $0.03 \mathrm{MPa}$ suction pressure are recommended for intraoperative salvage autotransfusion.
\end{abstract}

Key words: Intraoperative salvage autotransfusion; Plasma-free hemoglobin; Creatinine clearance

\section{Introduction}

Besides financial burden, allogenic transfusion remains a challenge considering the risk of developing transfusion-transmitted virus and bacterial infections, acute lung injury and circulatory overload, hemolytic and allergic reactions, variant Creutzfeldt-Jakob disease, and even death (1-4). Thus, intraoperative blood salvage should be considered. With carefully selected surgical patients, intraoperative salvage autotransfusion can provide erythrocytes of a higher quality with less blood storage and immunological challenge $(5,6)$. Considering the risks, intraoperative salvage autotransfusion may be more cost-effective than allogeneic transfusion. The global medical community has increasingly moved from allogeneic towards autologous blood transfusions.

Intraoperative salvage autotransfusion is reported to affect post-operative renal function $(7,8)$. In the process of retrieving and transfusion of hematochezia, erythrocytes are sucked, filtered, and separated by vacuum aspiration, which will cause some degree of hemolysisrelated deterioration of renal function. In order to achieve maximum clinical benefit and minimum adverse effect, the negative suction pressure, the size of the suction tip, and the air contact during suction were investigated in a previous report, and it is estimated that air contact is a major concern (9). The Fresenius Kabi Continuous AutoTransfusion System is standardly utilized to aspirate in the middle of the pool of blood to minimize air contact (10), and the balance between the volume of transfusion and vacuum suction pressure was assessed in that investigation. In order to minimize the mechanical breakage of recycled erythrocytes, the vacuum suction pressure is recommended to not exceed $0.02 \mathrm{MPa}(150 \mathrm{mmHg})$ by previous research (11), while others found that erythrocytes are not affected even at $0.04 \mathrm{Mpa}(12)$. It is believed that the concentration of free hemoglobin (FHB) in the recovered blood is positively correlated with the occurrence of hepato-renal function insufficiency, and up to $1 \mathrm{~g} / \mathrm{L} \mathrm{FHB}$ can cause renal function damage. More than five units of autologous blood transfusion could increase the incidence of renal failure after surgery.

Correspondence: Biyu Wu: <wubiyu390@163.com>

${ }^{*}$ These authors contributed equally to this work. 
This investigation was designed to comprehensively evaluate the effect of transfusion volume and suction pressure on renal function, which will help to set up a unified standard of intraoperative salvage autotransfusion.

\section{Material and Methods}

\section{Study subjects}

This investigation was performed in Quanzhou First Hospital of Fujian Province, and the protocols were approved by the Ethical Committee of Quanzhou First Hospital. Study design and procedures are shown in Figure S1. A total of 936 typical cases that underwent surgery using the Continuous AutoTransfusion System (CATS $^{\circledR \text { plus }}$, Fresenius Kabi, Germany) were screened from January 2016 to December 2018. Inclusion criteria were: over 18 years of age; willing to participate and sign an informed consent; and underwent orthopedic surgery, cardiovascular surgery, organ transplant surgery, brain surgery, emergency surgery, and other surgeries. Exclusion criteria were: surgical patients with comorbidities such as hypertension, diabetes mellitus, chronic obstructive pulmonary disease, and chronic renal disease; surgical field blood contaminated with digestive, bile, urine, and amniotic fluid; surgical field blood at risk of contamination in open trauma; blood conservation beyond $6 \mathrm{~h}$; patients with infectious diseases; patients with malignant tumors and those who died during or within $72 \mathrm{~h}$ after surgery; patients with kidney injury before operation. After evaluation, a total of 625 eligible patients were enrolled in the final investigation.

\section{Continuous autotransfusion procedure}

The CATS ${ }^{\text {plus }}$ circuit was primed and purged with 3000 $\mathrm{mL}$ saline $(0.9 \%)$ mixed with $30,000 \mathrm{IU}$ of sodium heparin. A double-lumen suction catheter specific for blood collection was utilized to salvage the bloodshed from the surgical field. Salvaged blood was suctioned with different vacuum pressures according to the study design ( 0.01 , $0.015,0.02$, and $0.03 \mathrm{MPa}$ ), and further collected into the reservoir of the CATS ${ }^{\text {plus }}$. High-quality wash performed with the CATS ${ }^{\text {plus }}$ was processed to minimize the residual FHB ( $<100 \mathrm{mg} / \mathrm{dL}$ ), and the separated erythrocytes were further collected and transfused into the patients. Residual heparin levels were guaranteed to be less than or equal to $0.1 \mathrm{IU} / \mathrm{mL}$ in all post-treatments to minimize the clinical risk for intra- or post-operative hemorrhage.

\section{Demographical and hematological variables}

Age, gender, body mass index (BMI), and smoking habit were obtained and recorded. Hematological variables, such as blood urea nitrogen (BUN), blood creatinine, aspartate aminotransferase (AST), alanine aminotransferase $(A L T)$, plasma $F H B$, and creatinine clearance (CCr), were measured.

\section{Statistical analysis}

GraphPad Prism v7.0 software (GraphPad Software, Inc., USA) was used to analyze the data. Numerical variables are reported as means $\pm S D$. Categorical data are reported as percentage (\%) and were compared between groups by Pearson chi-squared and Fisher's Exact tests. Because the data of FHB and $\mathrm{CCr}$ were not in a normal distribution (Kolmogorov Smirnov, $\mathrm{P}<0.05$ ), the Mann Whitney test was used to test the statistical significance of FHB and CCr. A significance level of $\mathrm{P}<0.05$ was used in all tests.

\section{Results}

\section{Clinical characteristics}

Preoperative data (BMI, serum BUN, blood creatinine, AST, and ALT) of participants involved in this investigation are reported in Table 1. Age, gender, smoking habit, as well as types of surgery are also indicated in Table 1. The participants were further randomly assigned to different groups according to the volume of blood transfusion $(2,3$, 4,5 , and $>5$ units) and suction pressure (0.01, 0.015, 0.02 , and $0.03 \mathrm{MPa}$ ) (Table 2).

Table 1. Characteristics of study subjects.

\begin{tabular}{lc}
\hline Variables & Mean \pm SD or number (\%) \\
\hline Gender & \\
Male & $349(55.8 \%)$ \\
Female & $276(44.2 \%)$ \\
Age & \\
$<30$ years & $34(5.4 \%)$ \\
$30-45$ years & $137(21.9 \%)$ \\
$46-60$ years & $285(45.6 \%)$ \\
$>60$ years & $169(27.1 \%)$ \\
BMI & \\
$<18.5$ & $16(2.6 \%)$ \\
$18.5-24.9$ & $267(42.7 \%)$ \\
$25-30$ & $321(51.3 \%)$ \\
$>30$ & $21(3.4 \%)$ \\
Smoking habit & $127(20.3 \%)$ \\
BUN (mg/dL) & $16.4 \pm 6.3$ \\
Blood creatinine (mg/dL) & $0.87 \pm 0.39$ \\
AST (IU/L) & $37 \pm 15$ \\
ALT (IU/L) & $54 \pm 36$ \\
Operation type & \\
Orthopedic surgery & $105(16.8 \%)$ \\
Cardiovascular surgery & $123(19.7 \%)$ \\
Organ transplant surgery & $86(13.8 \%)$ \\
Brain surgery & $94(15.0 \%)$ \\
Emergency surgery & $101(16.2 \%)$ \\
Others & $116(18.5 \%)$ \\
\hline
\end{tabular}

BMI: body mass index $[<18.5$ (low weight); 18.5-24.9 (normal); 25-30 (overweight), and $>30$ (obese)]; BUN: blood urea nitrogen; AST: aspartate aminotransferase, ALT: alanine aminotransferase. 
Transfusion load and suction pressure related to risk of renal function damage

Postoperative renal function change was indicated by the alteration of plasma $\mathrm{FHB}$ and $\mathrm{CCr}$. A significant difference in $\mathrm{FHB}$ and $\mathrm{CCr} 24 \mathrm{~h}$ post-operation compared with pre-operation in the case of $0.03 \mathrm{MPa}$ suction and $\geqslant 4$ units transfusion and $0.02 \mathrm{MPa}$ and $>5$ units transfusion $(\mathrm{P}<0.05$ or $\mathrm{P}<0.01)$ (Table 3 and Table 4) was found, which indicated that both $>5$ units transfusion and $0.03 \mathrm{MPa}$ suction plus $\geqslant 4$ units transfusion would increase the risk of renal function damage.

Table 2. Subjects were assigned to different number of transfusion units and pressures of intraoperative salvage autotransfusion.

\begin{tabular}{lccccc}
\hline Suction pressure & 2 units & 3 units & 4 units & 5 units & $>5$ units \\
\hline $0.01 \mathrm{MPa}$ & $26(4.2 \%)$ & $29(4.6 \%)$ & $34(5.4 \%)$ & $19(3.0 \%)$ & $19(3.0 \%)$ \\
$0.015 \mathrm{MPa}$ & $37(5.9 \%)$ & $47(7.5 \%)$ & $38(6.1 \%)$ & $27(4.3 \%)$ & $18(2.9 \%)$ \\
$0.02 \mathrm{MPa}$ & $39(6.2 \%)$ & $53(8.5 \%)$ & $43(6.9 \%)$ & $36(5.8 \%)$ & $21(3.4 \%)$ \\
$0.03 \mathrm{MPa}$ & $42(6.7 \%)$ & $33(5.3 \%)$ & $24(3.8 \%)$ & $23(3.7 \%)$ & $17(2.7 \%)$ \\
\hline
\end{tabular}

Table 3. Plasma free hemoglobin $(\mathrm{mg} / \mathrm{dL})$ content in pre- and post-operative patients at $24 \mathrm{~h}$.

\begin{tabular}{|c|c|c|c|c|c|}
\hline Suction pressure & 2 units & 3 units & 4 units & 5 units & $>5$ units \\
\hline \multicolumn{6}{|l|}{$0.01 \mathrm{MPa}$} \\
\hline Pre-operation & $7.73 \pm 5.21$ & $8.91 \pm 6.31$ & $6.32 \pm 4.98$ & $9.21 \pm 6.12$ & $7.12 \pm 5.61$ \\
\hline Post-operation & $15.16 \pm 7.23$ & $21.47 \pm 7.93$ & $26.05 \pm 10.42$ & $31.11 \pm 14.65$ & $45.65 \pm 12.34^{*}$ \\
\hline \multicolumn{6}{|l|}{$0.015 \mathrm{MPa}$} \\
\hline Pre-operation & $6.87 \pm 5.03$ & $8.32 \pm 5.82$ & $7.92 \pm 4.82$ & $7.54 \pm 5.55$ & $8.11 \pm 6.04$ \\
\hline Post-operation & $13.89 \pm 7.14$ & $25.23 \pm 9.27$ & $28.38 \pm 12.16$ & $29.75 \pm 13.28$ & $53.05 \pm 14.18^{*}$ \\
\hline \multicolumn{6}{|l|}{$0.02 \mathrm{MPa}$} \\
\hline Pre-operation & $9.14 \pm 6.31$ & $8.27 \pm 5.72$ & $7.31 \pm 5.19$ & $7.79 \pm 6.05$ & $7.38 \pm 5.23$ \\
\hline Post-operation & $16.27 \pm 7.12$ & $28.12 \pm 13.11$ & $32.65 \pm 15.21$ & $48.92 \pm 13.27^{*}$ & $72.05 \pm 18.24^{*}$ \\
\hline \multicolumn{6}{|l|}{$0.03 \mathrm{MPa}$} \\
\hline Pre-operation & $6.94 \pm 4.90$ & $7.67 \pm 5.81$ & $8.81 \pm 5.94$ & $9.03 \pm 5.92$ & $7.49 \pm 4.94$ \\
\hline Post-operation & $30.73 \pm 11.79$ & $42.87 \pm 13.29^{*}$ & $62.15 \pm 18.57^{*}$ & $87.34 \pm 25.12^{*}$ & $121.28 \pm 33.73^{* \star}$ \\
\hline
\end{tabular}

Data are reported as means $\pm \mathrm{SD}$. ${ }^{*} \mathrm{P}<0.05$, ${ }^{*} \mathrm{P}<0.01$ compared to pre-operation at the same condition during the intraoperative salvage autotransfusion (paired $t$-test).

Table 4. Creatinine clearance $\left(\mathrm{mL} \cdot \mathrm{min}^{-1} \cdot\left(1.73 \mathrm{~m}^{2}\right)^{-1}\right)$ in pre-operative and $24 \mathrm{~h}$ post-operative patients.

\begin{tabular}{|c|c|c|c|c|c|}
\hline Suction pressure & 2 units & 3 units & 4 units & 5 units & $>5$ units \\
\hline \multicolumn{6}{|l|}{$0.01 \mathrm{MPa}$} \\
\hline Pre-operation & $92 \pm 7$ & $89 \pm 8$ & $90 \pm 7$ & $93 \pm 10$ & $88 \pm 9$ \\
\hline Post-operation & $84 \pm 9$ & $83 \pm 10$ & $80 \pm 10$ & $76 \pm 10$ & $45 \pm 12^{*}$ \\
\hline \multicolumn{6}{|l|}{$0.015 \mathrm{MPa}$} \\
\hline Pre-operation & $89 \pm 10$ & $91 \pm 9$ & $88 \pm 11$ & $90 \pm 9$ & $91 \pm 9$ \\
\hline Post-operation & $81 \pm 9$ & $76 \pm 10$ & $77 \pm 12$ & $70 \pm 13$ & $47 \pm 14^{*}$ \\
\hline \multicolumn{6}{|l|}{$0.02 \mathrm{MPa}$} \\
\hline Pre-operation & $92 \pm 10$ & $86 \pm 11$ & $89 \pm 10$ & $94 \pm 13$ & $91 \pm 11$ \\
\hline Post-operation & $83 \pm 12$ & $74 \pm 13$ & $71 \pm 12$ & $63 \pm 9^{*}$ & $42 \pm 10^{*}$ \\
\hline \multicolumn{6}{|l|}{$0.03 \mathrm{MPa}$} \\
\hline Pre-operation & $89 \pm 13$ & $90 \pm 9$ & $88 \pm 7$ & $91 \pm 12$ & $89 \pm 9$ \\
\hline Post-operation & $72 \pm 10$ & $69 \pm 12$ & $60 \pm 11^{*}$ & $51 \pm 10^{*}$ & $35 \pm 9^{* *}$ \\
\hline
\end{tabular}

Data are reported as means $\pm S D$. ${ }^{*} P<0.05$, ${ }^{*} P<0.01$ compared to pre-operation at the same condition during intraoperative salvage autotransfusion (paired $t$-test). 


\section{Less than 4 units of transfusion volume caused no harm to renal function}

To decipher the relative long-term effect of transfusion volume and suction pressure on the risk of developing renal function damage, a time-course detection and analysis were performed. Under the situation of $0.02 \mathrm{MPa}$ suction ( $>5$ units transfusion), the levels of $\mathrm{FHB}$ and $\mathrm{CCr}$ altered significantly compared with the pre-operation condition at $6,12,24$, and $72 \mathrm{~h}$, as expected $(\mathrm{P}<0.05$ or $\mathrm{P}<0.01$, Table 5$)$. Three units transfusion caused no change in $\mathrm{FHB}$ and $\mathrm{CCr}$, while the change of $\mathrm{FHB}$ and $\mathrm{CCr}$ returned to normal after $24 \mathrm{~h}$ postoperation with 4 units transfusion, and all of these indicated that a transfusion volume less than four units should be safe.

\section{Suction pressure less than $0.03 \mathrm{MPa}$ caused no harm to renal function}

The effect of suction pressure on renal function was further investigated under the 3 units transfusion. The changes of $\mathrm{FHB}$ and $\mathrm{CCr}$ at 6 and $12 \mathrm{~h}$ post-operation was significant compared with pre-operation $(\mathrm{P}<0.05$ or $P<0.01$ ), while such changes were restored to normal at $72 \mathrm{~h}$ post-operation at $0.03 \mathrm{MPa}$ suction (Table 6). Only at the 6-h time-point was a FHB change observed at 0.02 MPa suction, which was restored at $12 \mathrm{~h}$ post-operation. All of these indicated that the recommended pressure for vacuum suction should be less than $0.03 \mathrm{MPa}$.

\section{Discussion}

In this investigation, both FHB and $\mathrm{CCr}$ were utilized to indicate renal function. Intraoperative salvage hemolysis can release $\mathrm{FHB}$, which can precipitate in the renal tubules with resultant tubular dysfunction (13-15). In intraoperative salvage autotransfusion, the washing process can remove FHB before re-infusion, and less than $100 \mathrm{mg} / \mathrm{dL} \mathrm{FHB}$ is recommended to minimize the effect on

Table 5. Plasma free hemoglobin (FHB) and creatinine clearance $(\mathrm{CCr})$ in pre-operative and $6,12,24$, and $72 \mathrm{~h}$ post-operative patients under 0.02 Mpa pressure.

\begin{tabular}{|c|c|c|c|c|c|}
\hline & Preoperative & $6 \mathrm{~h}$ & $12 \mathrm{~h}$ & $24 \mathrm{~h}$ & $72 \mathrm{~h}$ \\
\hline \multicolumn{6}{|l|}{$\mathrm{FHB}, \mathrm{mg} / \mathrm{dL}$} \\
\hline 2 units & $9.14 \pm 6.31$ & $32.36 \pm 16.27$ & $24.47 \pm 7.62$ & $16.27 \pm 7.12$ & $10.34 \pm 6.51$ \\
\hline 3 units & $8.27 \pm 5.72$ & $36.91 \pm 10.85$ & $30.61 \pm 10.79$ & $28.12 \pm 13.11$ & $20.16 \pm 9.42$ \\
\hline 4 units & $7.31 \pm 5.19$ & $43.68 \pm 12.37^{*}$ & $34.95 \pm 11.64$ & $32.65 \pm 15.21$ & $22.39 \pm 9.94$ \\
\hline 5 units & $7.79 \pm 6.05$ & $113.61 \pm 20.33^{* *}$ & $75.77 \pm 17.72^{*}$ & $48.92 \pm 13.27^{*}$ & $31.75 \pm 14.12$ \\
\hline$>5$ units & $7.38 \pm 5.23$ & $135.42 \pm 26.87^{\star *}$ & $106.45 \pm 19.85^{\star \star}$ & $72.05 \pm 18.24^{*}$ & $53.39 \pm 16.11^{*}$ \\
\hline \multicolumn{6}{|c|}{$\mathrm{CCr}, \mathrm{mL} \cdot \mathrm{min}^{-1} \cdot\left(1.73 \mathrm{~m}^{2}\right)^{-1}$} \\
\hline 2 units & $92 \pm 10$ & $75 \pm 13$ & $78 \pm 9$ & $83 \pm 12$ & $90 \pm 14$ \\
\hline 3 units & $86 \pm 11$ & $71 \pm 11$ & $72 \pm 11$ & $74 \pm 13$ & $88 \pm 9$ \\
\hline 4 units & $89 \pm 10$ & $63 \pm 10^{*}$ & $65 \pm 9^{*}$ & $71 \pm 12$ & $83 \pm 10$ \\
\hline 5 units & $94 \pm 13$ & $39 \pm 10^{*}$ & $46 \pm 12^{*}$ & $63 \pm 9^{*}$ & $67 \pm 10^{*}$ \\
\hline$>5$ units & $91 \pm 11$ & $36 \pm 12^{*}$ & $39 \pm 9^{*}$ & $42 \pm 10^{*}$ & $53 \pm 11^{*}$ \\
\hline
\end{tabular}

Data are reported as means $\pm \mathrm{SD}$. ${ }^{*} \mathrm{P}<0.05,{ }^{* *} \mathrm{P}<0.01$ compared to pre-operation at the same condition during intraoperative salvage autotransfusion (paired $t$-test).

Table 6. Plasma free hemoglobin (FHB) and creatinine clearance $(\mathrm{CCr})$ in pre-operative and $6,12,24$, and $72 \mathrm{~h}$ post-operative patients under 3 transfusion units.

\begin{tabular}{|c|c|c|c|c|c|}
\hline Suction pressure & Preoperative & $6 \mathrm{~h}$ & $12 \mathrm{~h}$ & $24 \mathrm{~h}$ & $72 \mathrm{~h}$ \\
\hline \multicolumn{6}{|l|}{$\mathrm{FHB}, \mathrm{mg} / \mathrm{dL}$} \\
\hline $0.01 \mathrm{MPa}$ & $8.91 \pm 6.31$ & $31.65 \pm 14.48$ & $24.36 \pm 12.29$ & $21.47 \pm 7.93$ & $13.52 \pm 9.11$ \\
\hline $0.015 \mathrm{MPa}$ & $8.32 \pm 5.82$ & $35.14 \pm 13.95$ & $28.24 \pm 14.17$ & $25.23 \pm 9.27$ & $16.86 \pm 8.42$ \\
\hline $0.02 \mathrm{MPa}$ & $8.27 \pm 5.72$ & $64.97 \pm 15.26^{*}$ & $34.75 \pm 16.63$ & $28.12 \pm 13.11$ & $21.72 \pm 9.78$ \\
\hline $0.03 \mathrm{MPa}$ & $7.67 \pm 5.81$ & $98.86 \pm 18.56^{\star *}$ & $68.25 \pm 14.47^{*}$ & $42.87 \pm 13.29^{*}$ & $35.25 \pm 14.17$ \\
\hline \multicolumn{6}{|c|}{$\mathrm{CCr}, \mathrm{mL} \cdot \mathrm{min}^{-1} \cdot\left(1.73 \mathrm{~m}^{2}\right)^{-1}$} \\
\hline $0.01 \mathrm{MPa}$ & $89 \pm 8$ & $73 \pm 13$ & $79 \pm 14$ & $83 \pm 10$ & $83 \pm 15$ \\
\hline $0.015 \mathrm{MPa}$ & $91 \pm 9$ & $70 \pm 12$ & $73 \pm 11$ & $76 \pm 10$ & $85 \pm 9$ \\
\hline $0.02 \mathrm{MPa}$ & $86 \pm 11$ & $68 \pm 15$ & $75 \pm 16$ & $74 \pm 13$ & $81 \pm 13$ \\
\hline $0.03 \mathrm{MPa}$ & $90 \pm 9$ & $46 \pm 14^{*}$ & $52 \pm 12^{*}$ & $69 \pm 12$ & $73 \pm 13$ \\
\hline
\end{tabular}

Data are reported as means $\pm \mathrm{SD}$. ${ }^{*} \mathrm{P}<0.05$, ${ }^{*} \mathrm{P}<0.01$ compared to pre-operation at the same condition during intraoperative salvage autotransfusion (paired $t$-test). 
renal function. Such concentration of FHB is well below the standard of banked blood, which will show no deleterious effects on renal function after transfusion. $\mathrm{CCr}$ is a parameter that can be utilized to assess the excretory function of the kidneys (16-18), and renal dysfunction can be defined as a decrease of $\mathrm{CCr}(<60$ $\mathrm{mL} / \mathrm{min})(19)$.

Intraoperative salvage autotransfusion performed by the CATS $^{\text {plus }}$ system has some advantages, such as higher oxygen-carrying capacity and lower volume requirement for transfusion. The efficiency of erythrocyte collection during cell salvage can be attributed to suction pressure. Previous investigations suggest that minimal suction pressures and a suction tip with a relatively large diameter should be adopted to aspirate blood from a surgical field to minimize blood-air interfaces and maximize the efficiency of erythrocyte recovery $(11,20)$. The fast-moving foams produced by air aspiration during blood suction will burst in the negative pressure environment and generate a mechanical shear force on the erythrocyte $(9,21,22)$. In this investigation, we found that a suction pressure of less than $0.03 \mathrm{MPa}$ should be used for orthopedic surgery, cardiovascular surgery, organ transplant surgery, brain surgery, and emergency surgery, which can help guide the clinical application of intraoperative salvage autotransfusion. Minimum initial blood volume is required by the CATS ${ }^{\text {plus }}$ system to process; in this research, less than four units transfusion was determined for minimal renal function damage $(23,24)$.

The introduction and development of minimally invasive surgery will limit the utilization of intraoperative salvage autotransfusion due less blood loss and transfusion requirements (25-27). Considering cost-to-benefit ratios, such as lower infection rates and shorter hospital stays, intraoperative salvage autotransfusion can still benefit several patients. In addition, allogeneic transfusion, but not autologous transfusion, could shift an immune deviation towards a $\mathrm{T}$ helper 2-type response. Such a shift is associated with a gene transcription profile characteristic of immunosuppression, which may suppress natural killer cells and cytotoxic T-cells, and activate regulatory $\mathrm{T}$ cells to down-regulate cellular immunity $(25,28,29)$. Although the long-term immune shifting effect

\section{References}

1. East JM, Viau-Lapointe J, Mccredie VA. Transfusion practices in traumatic brain injury. Curr Opin Anesthesiol 2018; 31: 219-226, doi: 10.1097/ACO.0000000000000566.

2. Roberts $\mathrm{GH}$. Transfusion-related acute lung injury (TRALI). Clin Lab Sci 2004; 17: 133-135.

3. Seifried E, Mueller MM. Blood transfusion: one unit too much or one unit too few-which strategy poses the smallest risk to the patient? ISBT Sci Series 2017; 13. still needs further detailed analysis, intraoperative salvage autotransfusion might be a safe option in the immune context. In addition to renal function, the influence of intraoperative salvage autotransfusion on proinflammatory cytokines, platelet activation, coagulation, fibrinolysis, and hemolysis factors should also be considered in clinical practice, as reported $(10,30,31)$, which will be analyzed in a future clinical study. All of these indicate that in addition to the more detailed evaluation of renal function by glomerular filtration rate and blood urea nitrogen, immune function change induced by intraoperative salvage autotransfusion should also be studied.

It must be mentioned that prolonged large-volume autotransfusion may cause coagulopathy due to the dilution of clotting factors with transfusions. Thus, together with appropriate transfusion load and suction pressure, regular coagulation function or close patient monitoring is required $(32,33)$. The long-term effect of the tested transfusion load and suction pressure on renal function was not investigated in this study, and such limitation should also be considered.

Our investigation has both scientific and practical implications for the utilization of intraoperative salvage autotransfusion, which will help clinicians prescribe the appropriate amount of autotransfusion volume and suction pressure.

\section{Conclusion}

Although a more precise design and multi-center investigation are needed, this study showed that less than four units transfusion and less than $0.03 \mathrm{MPa}$ suction pressure may be recommended for intraoperative salvage autotransfusion.

\section{Supplementary Material}

Click here to view [pdf].

\section{Acknowledgments}

The study was supported by the Quanzhou Science and Technology Program Project in Medical and Health (2018Z093).

4. Polanco-García M, Capielo AM, Miret X, Chamero A, Sainz $J$, Revilla $E$, et al. Effectiveness of a patient blood management protocol on reduction of allogenic red blood cell transfusions in orthopedic surgery. Med Clin 2019; 152: 9097, doi: 10.1016/j.medcli.2018.04.021.

5. Catling S, Wrench I. Cell salvage at caesarean section: the need for an evidence-based approach. BJOG 2010; 117: 122-123, doi: 10.1111/j.1471-0528.2009.02394.x. 
6. Craig EK, Yazer MH, Waters JH. Red blood cell salvage analysis from clotted blood. Blood Transfus 2019; 17: 146150, doi: 10.2450/2018.0008-18.

7. Song Y, Li R, Gu XH, Gong XJ, Zhang G, Wu SM, et al. Effects of blood washing and autotransfusion during cardiopulmonary bypass on erythrocyte immune and kidney function [in Chinese]. Zhonghua Yi Xue Za Zhi 2006; 86: 2293-2296.

8. Murphy GJ, Rogers CS. Safety, efficacy, and cost of intraoperative cell salvage and autotransfusion after offpump coronary artery bypass surgery: a randomized trial. J Thoracic Cardiovasc Surg 2005; 130: 20-28, doi: 10.1016/ j.jtcvs.2004.12.006.

9. An SB, Choi ES, Ahn W. Suction conditions for minimizing the production of free hemoglobin during blood salvage using an autotransfusion apparatus. Korean $\mathrm{J}$ Anesthesiol 2011; 60: 266-271, doi: 10.4097/kjae.2011.60.4.266.

10. Reents W, Babin-Ebell J, Misoph MR, Schwarzkopf A, Elert O. Influence of different autotransfusion devices on the quality of salvaged blood. Ann Thorac Surg 1999; 68: 5862, doi: 10.1016/S0003-4975(99)00472-5.

11. Waters $\mathrm{JH}$, Brandon $\mathrm{W}$, Yazer $\mathrm{MH}$, Kameneva MV. Modification of suction-induced hemolysis during cell salvage. Anesth Analg 2007; 104: 684-687, doi: 10.1213/01. ane.0000255208.96685.2e.

12. Huidan L, Fengjiang Z, Zhihao $P$, Xiaofei $C$, Lina $Y$, Min $Y$. Effects of washed autologous blood transfusion on erythrocytic fragility in salvaged blood from diabetics [in Chinese]. Zhonghua Yi Xue Za Zhi 2014; 94: 491-494.

13. You D, Garcia AP, Ferridebarros F, Parsons D. Hemolysis following intraoperative cell salvage replacement in a scoliosis patient with sickle cell trait: a case report. Spine 2017; 42: E1331-E1333, doi: 10.1097/BRS.000000000000 2211.

14. Gregoretti S. Suction-induced hemolysis at various vacuum pressures: implications for intraoperative blood salvage. Transfusion 1996; 36: 57-60, doi: 10.1046/j.1537-2995. 1996.36196190516.x.

15. Sikorski RA, Rizkalla NA, Yang WW, Frank SM. Autologous blood salvage in the era of patient blood management. Vox Sang 2017; 112: 499-510, doi: 10.1111/vox.12527.

16. Wyss $M$, Kaddurahdaouk R. Creatine and creatinine metabolism. Physiol Rev 2000; 80: 1107-1213, doi: 10.1152/ physrev.2000.80.3.1107.

17. Wada H, Kanda J, Akahoshi Y, Nakano H, Ugai T, Yamasaki $\mathrm{R}$, et al. Impact of estimated glomerular filtration rate based on plasma cystatin $\mathrm{C}$ and serum creatinine levels before allogeneic hematopoietic cell transplantation. Hematology 2018; 23: 271-276, doi: 10.1080/10245332.2017.1396026.

18. Mangan C, Stott MC, Dhanda R. Renal physiology: blood flow, glomerular filtration and plasma clearance. Anaesth Intens Care Med 2018: S1472029918300584.

19. Klodell CT, Richardson JD, Bergamini TM, Spain DA. Does cell-saver blood administration and free hemoglobin load cause renal dysfunction? Am Surg 2001; 67: 44-47.

20. Michinaga Y, Takano T, Terasaki T, Miyazaki S, Kikuchi N, Okada K. Hemolytic characteristics of three suctioning systems for use with a newly developed cardiopulmonary bypass system. Perfusion 2019; 34: 136-142, doi: 10.1177/ 0267659118793559.

21. Li H, Lykotrafitis G. Erythrocyte membrane model with explicit description of the lipid bilayer and the spectrin network. Biophys J 2014; 107: 642-653, doi: 10.1016/j. bpj.2014.06.031.

22. Kuck L, Grau M, Simmonds MJ. Recovery time course of erythrocyte deformability following exposure to shear is dependent upon conditioning shear stress. Biorheology 2018; 54: 141-152, doi: 10.3233/BIR-17151.

23. Cyrille B, Goran L, Markus W, Cushing MM, Thorsten H. Evaluation of the minimum volume of salvage blood required for the successful use of two different autotransfusion devices. Paediatr Anaesth 2015; 25: 258-264, doi: 10.1111/ pan. 12535.

24. Zacharias T, Ahlschwede E, Dufour N, Romain F, TheissenLaval $O$. Intraoperative cell salvage with autologous transfusion in elective right or repeat hepatectomy: a propensity-score-matched case-control analysis. Can $J$ Surg 2018; 61: 105-113, doi: 10.1503/cjs.010017.

25. Frank SM, Rothschild JA, Masear CG, Rivers RJ, Merritt WT, Savage WJ, et al. Optimizing preoperative blood ordering with data acquired from an anesthesia information management system. Anesthesiology 2013; 118: 12861297, doi: 10.1097/ALN.0b013e3182923da0.

26. Moua PK, Nguyen CL, Piotrowski DA, Resch MJ, Tabassum T, Noonan K, et al. Surgical sponge blood salvage spinning device design and testing. J Med Eng Technol 2018; 42: 426-434, doi: 10.1080/03091902.2018.1543465.

27. Dhariwal SK, Khan KS, Allard S, Wilson M, Moore P. Does current evidence support the use of intraoperative cell salvage in reducing the need for blood transfusion in caesarean section? Curr Opin Obstet Gynecol 2014; 26: 425-430, doi: 10.1097/GCO.0000000000000116.

28. Kirkley SA, Cowles J, Pellegrini VD, Harris CM, Boyd AD, Blumberg N,. Blood transfusion and total joint replacement surgery: T helper 2 (TH2) cytokine secretion and clinical outcome. Transfus Med 2008; 8: 195-204, doi: 10.1046/ j.1365-3148.1998.00149.x.

29. Kirkley SA. Proposed Mechanisms of Transfusion-Induced Immunomodulation. Clin Diagn Lab Immunol 1999; 6: 652657, doi: 10.1128/CDLI.6.5.652-657.1999.

30. Dong P, Che J, Li X, Tian M, Smith FG. Quick biochemical markers for assessment of quality control of intraoperative cell salvage: a prospective observational study. J Cardiothorac Surg 2014; 9: 86, doi: 10.1186/1749-8090-9-86.

31. van der Merwe M, Lightfoot NJ, Munro JT, Boyle MJ. Intraoperative cell salvage use reduces the rate of perioperative allogenic blood transfusion in patients undergoing periacetabular osteotomy. J Hip Preserv Surg 2019; 6: 277283, doi: 10.1093/jhps/hnz039.

32. Klein AA, Arnold P, Bingham RM, Brohi K, Clark R, Collis R, et al. AAGBI guidelines: the use of blood components and their alternatives 2016. Anaesthesia 2016; 71: 829-842, doi: 10.1111/anae.13489.

33. Wellesley H, Pownall S. AAGBI Consent guidelines 2017should the advice about 16 and 17 -year-olds be amended? Anaesthesia 2017; 72: 656-657, doi: 10.1111/anae.13883. 